\section{PERSPECTIVISM AND SPECIAL RELATIVITY}

Abstract: The special theory of relativity holds significant interest for scientific perspectivists. In this paper, I distinguish between two related meanings of "perspectival," and argue that reference frames are perspectives, provided that perspectival means "being conditional" rather than "being partial." Framedependent properties such as length, time duration, and simultaneity, are not partially measured in a reference frame, but their measurements are conditional on the choice of frame. I also discuss whether the constancy of the speed of light depends on perspectival factors such as the idealized definition of the speed of light in a perfect vacuum and the Einstein synchronization convention. Furthermore, I argue for the view that the constancy of its speed is a robust property of light according to the conditions of currently acceptable experimental setups pertaining to special relativity, and conclude that this view supports perspectivism.

Keywords: special relativity; reference frame; perspectivism; realism; robustness

\section{MAHDI KHALILI}

Depart. of the Philosophy of Science Sharif University of Technology

\section{Perspektivismus a speciální relativita}

Abstrakt: Speciální teorie relativity je obzvláště zajímavá $z$ hlediska vědeckého perspektivismu. V tomto článku rozliším dva související významy pojmu "perspektiva“ a pokusím se ukázat, že vztažné soustavy lze chápat jako perspektivy za předpokladu, že perspektivou rozumíme spíše „být podminěny", a nikoli „být dílčí. Vlastnosti závislé na vztažné soustavě, jako je délka, časové trvání a simultánnost, nejsou $v$ dané vztažné soustavě měreny neúplně, ale jejich měřní jsou podmíněna výběrem vztažné soustavy. Rovněž se budu zabývat otázkou, zda stálost rychlosti světla závisí na perspektivních faktorech, jako je idealizovaná definice rychlosti světla $v$ dokonalém vakuu a Einsteinova synchronizační konvence. Na závěr se pokusím ukázat, že konstantní rychlost je robustní vlastností světla dle podminek aktuálně prìímaných experimentů týkajících se speciální relativity a že tento pohled podporuje perspektivismus.

Klíčová slova: speciální relativita; vztažná soustava; perspektivismus; realismus; robustnost

Azadi Ave, Tehran, Iran

PO Box: 11365-11155

email / mahdi7khalili@gmail.com

\footnotetext{
(c) (1) This work is licenced under the Creative Commons Attribution 4.0 International License.
} 


\section{Introduction}

Scientific perspectivism, recently developed by philosophers of science such as Ronald Giere, ${ }^{1}$ Bas van Fraassen, ${ }^{2}$ Paul Teller ${ }^{3}$ and Michela Massimi, ${ }^{4}$ is roughly the claim that our scientific knowledge is bounded by instrumental, theoretical, and historical perspectives. Objective knowledge of reality, in the sense of a view of nature "from nowhere," is unattainable.

In the context of the scientific realism debate, a well-developed perspectival reading of special relativity theory is still lacking. The theory of relativity is mentioned, but only in passing, by Massimi, ${ }^{5}$ by Philip Berghofer ${ }^{6}$ and by Peter W. Evans. ${ }^{7}$ Nonetheless, considering "reference frames" as perspectives is not an unprecedented idea. For instance, Van Fraassen ${ }^{8}$ does not object to using "perspective" in describing events in reference frames. ${ }^{9}$ Jenann Ismael ${ }^{10}$ also uses reference frames to discuss causation. In addition, in the

${ }^{1}$ Ronald Giere, Scientific Perspectivism (Chicago: University of Chicago Press, 2006); Ronald Giere, "Kuhn as Perspectival Realist," Topoi 32 (2013): 53-57; Ronald Giere, "Feyerabend's Perspectivism," Studies in History and Philosophy of Science 57 (2016): 137-41.

2 Bas C. van Fraassen, Scientific Representation: Paradoxes of Perspective (Oxford: Clarendon Press, 2008).

${ }^{3}$ Paul Teller, "Modeling, Truth, and Philosophy," Metaphilosophy 43, no. 3 (2012): 257-74; Paul Teller, "What Is Perspectivism, and Does It Count as Realism?," in Understanding Perspectivism: Scientific Challenges and Methodological Prospects, eds. Michela Massimi and Casey D. McCoy (New York: Routledge, 2020), 49-64.

${ }^{4}$ Michela Massimi, "Scientific Perspectivism and Its Foes," Philosophica 84, no. 1 (2012): 2552; Michela Massimi, "Four Kinds of Perspectival Truth," Philosophy and Phenomenological Research 96, no. 2 (2018): 342-59; Michela Massimi, "Perspectivism," in The Routledge Handbook of Scientific Realism, ed. Juha Saatsi (New York: Routledge, 2018), 164-75.

${ }^{5}$ Michela Massimi, "Realism, Perspectivism, and Disagreement in Science," Synthese (2019): 8.

${ }^{6}$ Philipp Berghofer, "Scientific Perspectivism in the Phenomenological Tradition," European Journal for Philosophy of Science 10 (2020): 12-13.

${ }^{7}$ Peter. W. Evans, "Perspectival Objectivity or: How I Learned to Stop Worrying and Love Observer-Dependent Reality," European Journal for Philosophy of Science 10 (2020): 19-20.

${ }^{8}$ Van Fraassen, Scientific Representation, 69-72.

${ }^{9}$ Van Fraassen advises "caution against [loose] talk of 'perspective' when discussing coordinates and frames of reference" (ibid., 69). However, he concludes his discussion thus: "the use of 'perspective' and 'perspectival' in connection with depictions of events in varying frames of reference cannot be banished completely." Van Fraassen agrees with Hermann Weyl who "refers to coordinate systems as 'the unavoidable residuum of the ego's annihilation"” (ibid., 71). Van Fraassen's reference to Weyl's quotation is through Thomas Ryckman, The Reign of Relativity: Philosophy of Physics 1915-1925 (Oxford: Oxford University Press, 2005), 134.

${ }^{10}$ Jenann Ismael, "How Do Causes Depend on Us? The Many Faces of Perspectivalism," Synthese 193, no. 1 (2016): 245-67. 
context of the metaphysics of spacetime, perspectival readings of special relativity have recently been suggested. I will discuss them in subsection 2.3.

I seek to bridge the gap between perspectivism and special relativity. My discussion is in the context of the scientific realism debate. I will clarify my usage of the term "perspective" based on a critical reading of Giere's scientific perspectivism. ${ }^{11}$ I present a perspectival reading of frame-dependent and frame-independent properties in special relativity. The frame-dependent properties that I will address are length, time duration, and simultaneity, while the frame-independent property that will be discussed is the constancy of the speed of light. According to the special theory of relativity, the constancy of this speed is a property of light. My focus is on the frameindependence of the speed of light, but the frame-independence of the laws of physics may also be discussed in a similar vein. ${ }^{12}$

Section 2 argues that inertial reference frames can be considered as perspectives provided that "perspectival" implies "being conditional" rather than "being partial." The term "conditionality" is preferable to "partiality" and, moreover, is essential to a perspectival account of truth. I also explain that frame-dependent properties are not mere appearances; thus, statements about them can be true. Section 3 addresses the constancy of the speed of light: this constancy is claimed to be conditional on factors such as the idealized definition of the speed of light and Einstein synchronization. While reference to these factors is not enough to provide convincing arguments for perspectivism, I argue that the constancy of this speed, as a "robust" property of light, is conditional on certain experimental setups, and this conditionality can support perspectivism. Section 4 summarizes and critically discusses the motivations for a perspectival reading of special relativity. I conclude that reference frames are genuine cases of perspectives. Furthermore, the constancy of the speed of light is a robust, rather than a non-perspectival, property of light in the domain of special relativity. Although the paper concentrates on special relativity, some comments about general relativity are made in section 5 .

\footnotetext{
${ }^{11}$ Giere, Scientific Perspectivism.

${ }^{12}$ On frame-dependent (or relative) and frame-independent (or absolute) properties in special relativity, see chap. 3 in Peter Kosso, Appearance and Reality: An Introduction to the Philosophy of Physics (Oxford: Oxford University Press, 1998).
} 


\section{Frame-Dependent Properties}

\subsection{The Basic Principles of Special Relativity}

To articulate special relativity, I follow Einstein's 1905 "principle" approach. I should first explain that Einstein ${ }^{13}$ makes a distinction between two kinds of theories: 1. principle theories, such as thermodynamics, which are formed when one raises empirical regularities about certain phenomena to the level of principles, and 2. constructive theories, such as the kinetic theory of gases, which explain certain phenomena by building up a picture of the reality underpinning the phenomena. Special relativity, according to Einstein, is a case of the former class of theories. ${ }^{14}$ The two basic principles of the special theory of relativity are: 1 . The principle of relativity - the laws of physics are invariant in all inertial frames of reference (i.e., reference frames with no acceleration $)^{15}$ and 2 . The principle of the constancy of the speed of light: the

${ }^{13}$ Albert Einstein, “Time, Space, and Gravitation," The Times (November 28, 1919).

${ }^{14}$ Thus, a constructive theory is needed to explain the underlying grounds of special relativity. Two "constructive" approaches to (special) relativity are proposed: the geometrical approach and the dynamical approach. According the former, the symmetry of Minkowski spacetime, which constitutes the constructive grounds of the theory, explains the Lorentz invariance of the dynamical laws. Lorentz transformations ultimately depend on the Minkowski geometry of spacetime, and accordingly, the geometric structure of spacetime accounts for specialrelativistic phenomena such as time dilation and length contraction. See Michel Janssen, "Drawing the Line Between Kinematics and Dynamics in Special Relativity," Studies in History and Philosophy of Modern Physics 40, no. 1 (2009): 26-52; Tim Maudlin, "Relativity and Space-Time Geometry," in The Routledge Companion to Philosophy of Physics, eds. Eleanor Knox and Alastair Wilson (London: Routledge, 2021); see also Michel Friedman, Foundations of Space-Time Theories (Princeton, NJ: Princeton University Press, 1983) for a classic defense of the geometrical approach. According to the dynamical approach, the Lorentz invariance of the dynamical laws provides the underpinning reality, and thus governs Minkowski spacetime. Time dilation and length contraction are at root due to Lorentz-invariant dynamics. Proponents of this approach "consider absolute space-time structure as a codification of certain key aspects of the [dynamical] behaviour of particles (and/or fields)." Harvey R. Brown, Physical Relativity: Spacetime Structure from a Dynamical Perspective (Oxford: Oxford University Press, 2005), 25; see also Harvey R. Brown and Oliver Pooley, "Minkowski SpaceTime: A Glorious Non-Entity," in The Ontology of Spacetime, ed. Dennis Dieks (Amsterdam: Elsevier, 2006); Harvey R. Brown and James Read, "The Dynamical Approach to Spacetime Theories," in The Routledge Companion to Philosophy of Physics, eds. Eleanor Knox and Alastair Wilson (London: Routledge, 2021). In this article I am neutral about the geometrical versus dynamical approach. It can be argued elsewhere that even if these approaches do not necessitate perspectivism, both are compatible with the perspectival understanding of special relativity.

15 "[T] he same laws of electrodynamics and optics will be valid for all frames of reference for which the equations of mechanics hold good." Albert Einstein, "On the Electrodynamics of 
speed of light in vacuum is constant independent of the motion of the light source. $^{16}$

Lorentz transformations transform the coordinates $(x, y, z, t)$ of a point or an event from one reference frame to another such that the constancy of the speed of light is preserved and the laws of physics remain invariant. These transformations have certain counterintuitive implications, such as the relativity of simultaneity, length contraction, and time dilation. While according to classical physics and common sense knowledge the values of position and speed are relative to the reference frame of the observer, in special relativity this holds true as well for properties such as simultaneity, length, and time duration.

For instance, when event ${ }_{1}$ and event ${ }_{2}$ are not causally connected, it may be that in frame ${ }_{1}$, event ${ }_{1}$ occurs before event ${ }_{2}$; in frame , $_{2}$, event occurs after $_{1}$ event $_{2}$; and in frame ${ }_{3}$, event ${ }_{1}$ and event ${ }_{2}$ occur simultaneously. For causally connected events, when event ${ }_{1}$ occurs before event ${ }_{2}$ in frame $_{1}$, this ordering cannot be changed in other reference frames, because in the physical world, without particles that travel faster than light (i.e., superluminal tachyons), it is impossible to change the ordering of events that lie within the light cones of each other. ${ }^{17}$ Accordingly, simultaneity is conditional on the choice of reference frame. Or, rather, this entails that the classical concept of simultaneity loses its meaning in special relativity theory.

\subsection{Reference Frames as Perspectives}

The concept of a "reference frame" is central to special relativity. A reference frame is defined as a state in space, time, and motion from which an observation/measurement is made. Indeed, Einstein's main breakthrough in 1905 was to explicate that a physical observation depends not only on the space- and time-state of the observer (which is trivially true), but also on the observer's relative speed with respect to the observed object. That is, in the definition of the reference frame, its motion should always be considered. Accordingly, a reference frame is described as an (ideal) observational state

Moving Bodies," in Hendrik A. Lorentz, Albert Einstein, Hermann Minkowski, and Hermann Weyl: The Principle of Relativity (New York: Dover Publications, 1952), 37-38.

16 " $[\mathrm{L}]$ ight is always propagated in empty space with a definite velocity $\mathrm{c}$ which is independent of the state of motion of the emitting body." Ibid., 38 .

${ }^{17}$ I would like to thank one of the reviewers for prompting me to be more precise on this subject. 
of position, time, and motion. ${ }^{18}$ The state of observation is either inertial or undergoing acceleration. Special relativity exclusively discusses inertial reference frames. My question is whether an inertial reference frame is an example of a "perspective" in its philosophical sense. To answer the question, I focus on Giere's conception of perspectives. He starts his argument concerning perspectivism by asserting that human vison is perspectival, in the sense of being partial.

For my purposes, maybe the most important feature of perspectives is that they are always partial. When looking out at a scene, a typical human trichromat is visually affected by only a narrow range of all the electromagnetic radiation available. $^{19}$

Then he extends his argument, asserting that scientific observations are also partial: that is, each observational instrument or detector responds to a specific feature of reality. For instance, a radio telescope receives only radio waves, and a gamma-ray telescope is sensitive only to gamma rays. Giere then proceeds still further and argues that scientific models are also partial. Only some features of a phenomenon are represented in a model, and others are eliminated. In this regard, models are similar to maps. "Maps are partial. Only some features of the territory in question are represented." ${ }^{20}$ The other meaning of perspective for Giere is dependence on a condition. According to him,

the strongest claims a scientist can legitimately make are of a qualified, conditional form: "According to this highly confirmed theory (or reliable instruments), the world seems to be roughly such and such." There is no way legitimately to take the further objectivist step and declare unconditionally: "This theory (or instrument) provides us with a complete and literally correct picture of the world itself." ${ }^{21}$

Do "being partial" and "being conditional" mean the same? Let me answer the question with respect to special relativity. It seems odd to maintain that an observer in a reference frame partially represents what is measured, in a similar way to which Giere speaks of the "partiality" of observations by

\footnotetext{
${ }^{18}$ Valuable comments by both of the reviewers for this journal helped me to define reference frames with greater precision.

${ }^{19}$ Giere, Scientific Perspectivism, 35.

${ }^{20}$ Ibid., 73, 76-78.

${ }^{21}$ Ibid., 5-6, emphases added.
} 
different instruments. When we see an astronomical object through different telescopes, each of them provides us with a different aspect of the object. These aspects are all incomplete, but each augments our understanding of the object. However, in special relativity, if an observer measures the length of an object from another frame, a further aspect of the object is not measured. The same aspect (length) is measured from a different frame.

For Giere, the notion of being partial is interconnected with that of being conditional. Accordingly, observations are always "conditional" on embodied instruments such as eyes and on technological instruments such as telescopes, in the sense that embodied or technological instruments represent "partial" aspects of reality. In other words, instruments form "perspectives," from which reality is represented "partially." Accordingly, for Giere, instruments constitute perspectives in either of these two equivalent senses: our observational knowledge is "conditional" on specific instruments, or because of their specificity instruments "partially" represent reality. Similarly, for Giere, models and theories constitute perspectives in either of these two equivalent senses: our theoretical knowledge is conditional on specific models, or because of their specificity models partially represent reality.

What Giere claims is, first, that our access to the world refers to our methods, which are always partial; second, he concludes from this that the results of these methods are always partial. So he characterizes both our methods and their results with the same term: partiality. However, I do not use the term "partiality," at least for the case of special relativity. I should explain that, first, I agree with Giere about partiality as a feature of perspectives, but I prefer to describe it as conditionality. Giere's use of "partial" refers to a type of constraint that defines a perspective; but, when put like this, it is a subspecies of a perspective being "conditional," and concerns about "partiality" collapse into the more inclusive notion of perspectives as being "conditional." Second, I am not sympathetic to the claim that the results of our methods can be described as "partial." A better description is that the results are always "conditional," as I will explain in the following.

In special relativity, the measurements of frame-dependent properties are conditional on reference frames, but it is incorrect to say that framedependent properties are the "partial" representations of an object. In other words, one can naturally say: on the condition that one observes from frame, the length of a rod is $\mathrm{L}_{1}$; on the condition that one observes from frame ${ }_{2}$, the length of the rod is $\mathrm{L}_{2}$, and so on. Also, no observation/measurement of the length can be made unconditionally, from nowhere. Therefore, if being perspectival means being conditional, a reference frame is a perspective. 
However, it is quite implausible, or indeed even meaningless to say, that $\mathrm{L}_{1}$ and $\mathrm{L}_{2}$ represent the rod "partially," or that each represents an "aspect" or a "part" of the rod.

Moreover, the conditionality (rather than partiality) of scientific knowledge is essential to the perspectival account of truth. "For a perspectivist, truth claims are always relative to a perspective"22 I understand the term "relative to" in Giere's statement as "conditional on." A truth claim in science is conditional on the instrumental or theoretical perspectives from which the claim is made. Regarding special relativity, frame-dependent properties such as length, time duration, and simultaneity are measured from the perspective of specific reference frames. Those measurements are completely true given the perspective from which the measurement is made. It is not the case that the frame-dependent properties are partially true in the perspective. Nor are those properties measurable unconditionally, from nowhere.

"Partial truth" is not a suitable term to explain the truthfulness of observations through instruments either. For instance, when one appropriately observes an astronomical object through a gamma-ray telescope, what is observed is completely ${ }^{23}$ true given the perspective of the gamma-ray telescope. It is not the case that what is observed is partially true "from nowhere" because, according to perspectivism, we have access to "nowhere" (or to "reality from no perspective whatsoever") neither completely nor partially. There is a substantial difference between "partial truth from nowhere" and "truth according to conditions." The term "partial truth" may mean the former, which is unavailable (if not nonsense). For this reason, I prefer not to use the term "partial truth." The expression "truth according to conditions" is clearly preferable because methods' partiality refers to a type of constraint that defines a perspective, and thus their partiality refers to their conditionality. Accordingly, a statement may be true according to bounded conditions.

It is also questionable that what is observed (by the gamma telescope) is to be considered as "partially true" because of the fact that some aspect of the observational result (say, the relative distances of objects observed) can also be observed by other instruments (such as a radio telescope, an X-ray telescope, etc.). As I shall explain below, "robustness" (rather than "par-

\footnotetext{
${ }^{22}$ Ibid., 81.

23 "Completely" here is in contrast with "partially" rather than "approximately" (meaning imprecise). Statistical approximations or approximate computations for Big Data analyses may be employed to provide astronomical or microscopic observations.
} 
tiality") is the suitable concept to explain the agreement of observations/ measurements made by independent instruments.

In sum, not only is "conditionality" more inclusive than "partiality," but it is also essential to a perspectival account of truth. In particular, the truth of the measurements of a frame-dependent property is conditional on the choice of frame. In the following I explain that frame-dependent properties are not mere appearances, so the statements about them can be true.

\subsection{Frame-Dependent Properties Are Not Mere Appearances}

Mere appearances are unreal. Thus, statements about them may encounter the same problems as apply to sentences about so-called nonexistent objects, such as Pegasus, the present King of France, the round square, and so forth. For instance, it is a matter of philosophical debate whether the sentence "Pegasus is a flying horse" is true, false, or truthless, or how the sentence "Pegasus does not exist" can be true when its subject is non-referring. ${ }^{24}$ The view that frame-dependent properties are mere appearances, illusory, or merely subjective, etc., has the same consequences, such that all statements about frame-dependent properties, even those about the length of ordinary objects, the time duration of everyday events, or even the position and speed of ordinary objects, face the same problems as encountered by sentences about non-existing objects.

However, it is certainly correct to say that statements about the position, speed, and length of ordinary objects or the time of ordinary events are either true or false. Ordinary objects and events exist, and therefore statements about them should not face the same problems as sentences about nonexistent objects. In general, it seems correct to say that frame-dependent properties are not the same as nonexistent objects. Perspectivism explains this intuition satisfactorily, by explaining that and why frame-dependent properties are real from the perspective of a specific reference frame. Therefore, statements about frame-dependent properties are either true or false given that perspective. Furthermore, according to special relativity, a wellformed statement about frame-dependent properties should include the reference frame from which the statement is made. Without specifying the frame, the statement is still incomplete, not yet constituted, and it is

\footnotetext{
${ }^{24}$ On nonexistent objects, see Maria Reicher, "Nonexistent Objects, " in Stanford Encyclopedia of Philosophy, accessed July 29, 2021, https://plato.stanford.edu/archives/win2019/entries/ nonexistent-objects.
} 
therefore impossible to determine whether it is true or false. Once the frame has been specified and the statement is properly constituted, it is either true or false. This can be explained by perspectival realism, according to which scientific claims are always made from perspectives, or given certain conditions. They cannot be unconditionally true, as knowledge from "nowhere" is unattainable.

In this regard, Martin Lipman ${ }^{25}$ has recently suggested a perspectival ontology for special relativity that underscores the frame-dependent of relative properties. Based on Kit Fine's fragmentalism, ${ }^{26}$ according to which reality is ontologically perspectival, Lipman argues that the instantiation of each frame-dependent property is a real fact in a "fragment" of reality. The difference between a "fragment" and Giere's "part" is that the former is an ontological term, while the latter is employed in an epistemological doctrine. According to fragmentalism, the accounts from all reference frames about frame-dependent properties are equally true because these accounts refer to real fragments of the world. As a result, frame-dependent properties are all real and not mere appearances; thus, statements about these real properties can be truthful.

One might not agree with ontological perspectivism and still support the view that different accounts from different frames are equally true, as Matias Slavov does. ${ }^{27} \mathrm{He}$ employs perspectival realism to argue that what makes statements about the present time true is the choice of a reference frame, as a perspective. There is no frame-independent present moment, thus truthmaking in statements about the present time depends on the choice of the perspective from which events are represented. Events are frame-independent, but representations of them constitute perspectival phenomena. Perspectival phenomena are neither mere appearances nor frame-independent facts. They are representations of frame-independent events. Therefore, frame-dependent properties are not mere appearances, and statements about them can be true. Because of his assumption of the frame-independence of events, Slavov's view need not buy into ontological pluralism; thus, his proposed perspectivism is metaphysically more parsimonious than Fine's and Lipman's fragmentalism. Slavov only presupposes

\footnotetext{
${ }^{25}$ Martin A. Lipman, “On the Fragmentalist Interpretation of Special Relativity," Philosophical Studies 177 (2020): 21-37.

${ }^{26}$ Kit Fine, "Tense and Reality," in Kit Fine: Modality and Tense: Philosophical Papers (Oxford: Oxford University Press, 2005), 261-320.

27 Matias Slavov, "Eternalism and Perspectival Realism about the 'Now," Foundations of Physics 50 (2020): 1398-410.
} 
the existence of frame-independent events and not of the whole frameindependent fragments of reality. ${ }^{28}$

When a rod is accelerated from one constant speed to another, the frame that co-moves with the rod in its initial state and the other frame that co-moves with the rode in its final state present two different accounts of the length of the rod. According to perspectivism, the accounts of the two frames are equally true. Lipman relates the two accounts to existing facts in reality. Slavov interprets them as two representations of one real event. Both views are perspectival, and are in unison with my claim that special relativity should be understood perspectivally. Yet, it seems to me that the latter view is preferable, because it is more metaphysically parsimonious than the other.

So far, I have argued that reference frames are perspectives, and that frame-dependent properties are perspectival. I will argue in the next section that the constancy of the speed of light can also be interpreted perspectivally ("perspectival" in the sense of being conditional).

\section{The Speed of Light}

\subsection{Constancy}

Conceptualizing reference frames as perspectives might seem problematic because, according to the principles of special relativity, the laws of physics and the speed of light in vacuum are not dependent on the reference frame of the observer. They are frame-independent.

However, a perspectivist can argue (with Giere) that the two principles contain perspectival factors that contribute to constituting the theory. On the condition that those factors are assumed, the physical world is the way that the theory of special relativity describes it. Thus, when an observer measures a frame-dependent property such as length, two kinds of perspectives are employed. First, the world is seen from the theoretical perspective that the two principles (containing perspectival factors) provide. Second, the observational perspective of that frame of reference is at work. Accordingly, frame-independence should not be understood as being independent of all perspectives (or from no perspective whatsoever); rather, it is to be independent only of the perspectives understood in terms of reference frames.

${ }^{28}$ For criticism of fragmentalism, see section 3 in Slavov, "Eternalism and Perspectival Realism." 
One might claim that something is independent of all perspectives when it is conditional on any perspective whatsoever; for example, regardless of which perspective one takes, one will get the constant speed $c$ for light. This claim, however, is of little help, because human beings have access only to historically available instrumental and theoretical perspectives, and not to "any perspective whatsoever." Accordingly, inasmuch as we are bounded human beings, we can never determine whether something is conditional on any perspective whatsoever. There may always be some theoretical or instrumental conditions that have not been taken into account. In this sense, therefore, it makes little sense to claim that something is perspective-independent. Moreover, regarding the example of the speed of light, whose constancy plays a central role in the framework of special relativity, we already know that the speed of light is not constant in "any perspective whatsoever." In general relativity, as I discuss in section 5, the speed of light is not the constant $c$. In the presence of gravity, i.e., in curved spacetime, measurement demonstrates that the speed of light varies. As a result, the speed of light is not universally (or: from any perspective whatsoever) constant.

Let us examine other possible perspectival factors in the framework of special relativity. One of these perspectival factors is the idealized concept of a perfect vacuum, by which the speed of light is defined and understood. According to Giere, the speed of light is defined in an idealized form, in a perfect vacuum - a condition unavailable in our messy world. He argues that

the definition [of the speed of light] is theoretical, the speed of light in a perfect vacuum. It is a constant in an idealized model. Our best theories tell us that there are no perfect vacuums to be found anywhere in the universe. So-called empty space is full of all kinds of "space dust." If it were not, we could see a lot further with optical telescopes than we can in fact see..$^{29}$

One might, however, argue that the idealized concept is used to express the limit state of several experimental results. Different earth-based or astronomical setups have thus far measured the speed of light (and of other electromagnetic waves and massless particles). These experimental measurements demonstrate that the constancy of the speed is a robust property of light (more on robustness below). Accordingly, the principle of the constancy of the speed of light is not a theoretical perspective but an empirical fact.

One could go further and argue that the idea of "a perfect vacuum," as an "idealized" concept, is rarely used in contemporary physics. If a given

\footnotetext{
${ }^{29}$ Giere, Scientific Perspectivism, 92.
} 
measurement requires it, the appropriate physical corrections are routinely made. That is, the interaction of light with atoms can be precisely calculated based on the known physical laws of optics, atomic theory, and fundamental quantum theory. Modern physical theories can take into account the impact of interstellar magnetic fields, particles and plasma on the propagation of light through a very sparse medium, thereby correcting the actual speed of light (as well as other parameters such as amplitude, polarization and dispersion). Even in a "pure vacuum state," when the light propagates through space without any usual matter, quantum field theory can calculate very subtle corrections arising from the mutual interaction of photons with virtual particles such as positrons and other photons.

In response to these objections, a perspectivist can still argue that the accepted theories used for such corrections are themselves conditional on certain theoretical assumptions and experimental results, none of which is ultimate or perspective-free. Indeed, I will, in a way, defend this claim. But let me first consider another perspectival motivation. It bears upon the fact that what is measured in experiments is the two-way speed of light from the emitter to the detector and back again. In order to measure the one-way speed of light the Einstein synchronization convention, according to which the speed of light is equal in different directions, must be employed. Therefore, an a priori convention is still needed to measure the (one-way) speed of light. Einstein established this convention in his 1905 paper on special relativity thus:

We have so far defined only an "A time" and a "B time." We have not defined a common "time" for $\mathrm{A}$ and $\mathrm{B}$, for the latter cannot be defined at all unless we establish by definition that the "time" required by light to travel from A to B equals the "time" it requires to travel from B to A. ${ }^{30}$

If two clocks are used to measure the one-way speed of light (one clock at the start point, where the emitter is, and the other where the detector is), the two clocks must be synchronized with each other. The synchronization of the clocks is equivalent to the Einstein synchronization convention. Wesley C. Salmon ${ }^{31}$ argues that a conventional factor is always involved in

\footnotetext{
${ }^{30}$ Einstein, "On the Electrodynamics of Moving Bodies," 40, emphasis in original.

${ }^{31}$ Wesley C. Salmon, "The Philosophical Significance of the One-Way Speed of Light," Noûs 11, no. 3 (1977): 253-92.
} 
the experiments that have historically been performed for the measurement of the speed of light. ${ }^{32}$

One should note that the conventionality thesis relies on a traditional interpretation of special relativity. In addition to Einstein, ${ }^{33}$ Reichenbach ${ }^{34}$ and Grünbaum ${ }^{35}$ argued that the standard synchronization has a conventional status. However, David Malament ${ }^{36}$ has cast doubt on this, arguing that the Einstein convention is the only definable simultaneity relation. Malament's objection is in turn criticized by Sahotra Sarkar and John Stachel ${ }^{37}$ as well as by Grünbaum..$^{38}$ The criticism of Sarkar and Stachel is in turn questioned by Robert Rynasiewicz, ${ }^{39}$ who himself vigorously defends the conventionality thesis. ${ }^{40}$ In this regard, Allen Janis maintains that "[t]he debate about conventionality of simultaneity seems far from settled." ${ }^{\text {"41 }}$ I cannot review this debate in detail here, because it would detract too much from the main subject of this article. It is worth mentioning, though, that (future) arguments in favor of the conventionality thesis would support the perspectival reading of the speed of light.

${ }^{32}$ Comparatively recently, Greaves, Rodríguezb, and Ruiz-Camacho have claimed that the one-way speed of light is experimentally measurable (see Eduardo Greaves, Michel Rodríguez, and J. Ruiz-Camacho, "A One-Way Speed of Light Experiment," American Journal of Physics 77, no. 10 (2009): 894-96), but Finkelstein's comment shows that they actually have measured the two-way speed of light (see Jerome Finkelstein, "One-Way Speed of Light?," American Journal of Physics 78, no. 8 (2010): 877).

${ }^{33}$ Einstein, "On the Electrodynamics of Moving Bodies."

${ }^{34}$ Hans Reichenbach, The Philosophy of Space \& Time (New York: Dover Publications, 1958).

${ }^{35}$ Adolf Grünbaum, Philosophical Problems of Space and Time (Dordrecht: D. Reidel, 1973).

${ }^{36}$ David Malament, "Causal Theories of Time and the Conventionality of Simultaniety," Nô̂s 11, no. 3 (1977): 293-300.

37 Sahotra Sarkar and John Stachel, "Did Malament Prove the Non-Conventionality of Simultaneity in the Special Theory of Relativity?," Philosophy of Science 66, no. 2 (1999): $208-20$.

${ }^{38}$ Adolf Grünbaum, "David Malament and the Conventionality of Simultaneity: A Reply," Foundations of Physics 40 (2010): 1285-97.

${ }^{39}$ Robert Rynasiewicz, "Definition, Convention, and Simultaneity: Malament's Result and its Alleged Refutation by Sarkar and Stachel," Philosophy of Science 68, no. 3 (2001): 345-57.

${ }^{40}$ Robert Rynasiewicz, "Simultaneity, Convention, and Gauge Freedom," Studies in History and Philosophy of Modern Physics 43, no. 2 (2012): 90-94.

${ }^{41}$ Allen Janis, "Conventionality of Simultaneity," in Stanford Encyclopedia of Philosophy, accessed July 29, 2021, https://plato.stanford.edu/archives/fall2018/entries/spacetime-convensimul. 


\subsection{Robustness}

(Two-way) light speeds are measured in several independent experiments. That is, the constancy of speed is a "robust" property of light. Does this "robustness" call perspectivism into question? I shall first discuss robustness and then explain its relationship with perspectivism.

The main idea of robustness can be found in Ian Hacking's "argument from coincidence," ${ }^{\prime 2}$ according to which if different microscopes-which work based on causally different mechanisms-detect the same microscopic entity, then one is justified to believe in the entity. More recently, based on William Wimsatt's view, ${ }^{43}$ Marcus Eronen provides an epistemological criterion for establishing the reality of things based on the concept of robustness. According to him, " $X$ is robust in the relevant scientific community at a certain time insofar as $X$ is detectable, measurable, derivable, producible, or explanatory in a variety of independent ways." ${ }^{\prime 44} X$ is a thing. It may be a scientific entity, a property, a phenomenon, or even an ordinary object.

A concept fairly similar to robustness that is employed in Giere's scientific perspectivism is "overlapping perspectives." When several independent setups manifest the same thing, "overlapping instrumental perspectives"45 are at work. When the theoretical explanation of a thing is presented in several theories, "overlapping theoretical perspectives"46 are available. Giere considers the evidence achieved from overlapping perspectives as "good evidence." Nevertheless, he argues that good evidence is still perspectival.

It is a commonplace that there can be many observational perspectives of the same objects. [...] Is this not good evidence that there is something "objectively" there? Indeed, this is good evidence that there is something there, but this need not be understood as knowledge in an "absolute objectivist" sense.

The simple but fundamental point is that to be an object detected in several different perspectives is not to be detected in no perspective whatsoever. All

\footnotetext{
${ }^{42}$ Ian Hacking, Representing and Intervening: Introductory Topics in the Philosophy of Natural Science (Cambridge: Cambridge University Press, 1983), 201.

${ }^{43}$ William C. Wimsatt, Re-Engineering Philosophy for Limited Beings: Piecewise Approximations to Reality (Cambridge, MA: Harvard University Press, 2007).

${ }^{44}$ Markus I. Eronen, "Robustness and Reality," Synthese 192, no. 12 (2015): 3967.

${ }^{45}$ Giere, Scientific Perspectivism, 57-58.

${ }^{46}$ Ibid., 92.
} 
observational claims made about the object are made in some perspective or other. ${ }^{47,48}$

Both Giere and robust realists avoid assuming that robust things are objective, understood from an ultimate viewpoint. Eronen's qualification that a thing is robust in a "relevant scientific community at a certain time" allows that a thing currently considered to be robust may turn out to be unreal in the conditions/perspectives that so far remain uninvestigated.

Regarding the speed of light, the speeds measured are always conditional on the validity scope of certain experimental setups, and this conditionality supports perspectivism. It is always possible that in a domain unexamined so far, it may turn out that the speed of light is not constant, as we actually know that in the presence of gravity, light speeds vary (see section 5). Accordingly, the constancy should not be read objectively (objective in the sense of being understood from an unqualified, unconditional viewpoint). Even if a one-way speed of light is measured, it can still be argued that the speed is measured according to some experimental setups in certain domains of investigation. In general, future conditions may not secure the findings of currently accepted measurements, or may show their bounded validity.

\section{Motivations for the Perspectivism of Special Relativity}

Thus far, I have supported two motivations for a perspectival interpretation of special relativity. The first motivation concerns frame-dependent properties and is a motivation specifically applying to perspectivism in special relativity. The second one concerns the speed of light and relies on a general motivation for perspectivism in science, including special relativity.

M1: Frame-dependent properties such as length, time duration, and simultaneity are conditional on the reference frame of the observer.

M2: The robustness of the constancy of light speeds is conditional on certain experimental setups and their theoretical interpretation, which are valid only within the scope of special relativity.

\footnotetext{
${ }^{47}$ Ibid., 57-58.

${ }^{48}$ Giere reiterates that "the same object can often be observed from several different perspectives, such as a nearby galaxy observed by both optical and radio telescopes. This is indeed good evidence that there is 'something' there, but that is scarcely knowledge in the objectivist sense. The knowledge we get comes from one perspective or another, not from no perspective at all. Multiplying perspectives does not eliminate perspectives." Ibid., 92.
} 
Critics might question the connection between the perspectivism of frame-dependent properties and that of the speed of light. They might even object that subsuming the relativity to reference frames and the dependence on experimental setups under a single notion produces a heterogeneous brand of "perspectivism." I agree that the role reference frames play in measuring frame-dependent properties is different from the role of experimental setups in measuring the speed of light. Be that as it may, M1 and $\mathrm{M} 2$ are the same in expressing the conditionality of scientific knowledge, which perspectivists emphasize. M2 is similar to M1 in a general feature: both are similar in expressing the conditionality of scientific knowledge within the special theory of relativity. But my point is that highlighting this similarity is worthwhile because what we know about the way reference frames work in special relativity can be used to clarify how perspectivism in experimental science should work. After all, the validity of our knowledge concerning the constancy of the speed of light is conditional on certain experimental conditions in a basically similar way that the validity of our knowledge of frame-dependent properties is conditional on the choice of frame. The validity scope of each of these two kinds of knowledge is qualified.

M1 and M2 enjoy different degrees of cogency and plausibility. M1 is the most powerful reason for a perspectival reading of special relativity. For a staunch critic of perspectivism, who questions the kind of arguments Giere provides in support of the claim that instrumental detections and theoretical models are perspectival, M2 may be unacceptable. However, even these critics cannot deny that the length of an object and the time duration of an event in special relativity depend on the choice of reference frame. Therefore, the perspectival character of frame-dependent properties suffices to accept that there is a genuine example of perspectivism in science. M2, on the other hand, is plausible if perspectival realism is correct in general. It is as compelling as other examples of perspectival knowledge discussed in the literature on perspectivism. That said, thanks to the fact that M1 is more evident than M2, the similarity between M1 and M2 can shed some light on the conditionality expressed in M2. Both frame-dependent properties and the experimental results concerning the constancy of the speed of light are valid in bounded conditions. In the remainder of this section, I defend M2 and M1 by setting aside some misunderstandings and by blocking some criticisms.

M2 rests on a general motivation for perspectivism applicable to all experimental results. According to this motivation, one can never claim 
that the results of currently valid experiments may not be untrue in novel, uninvestigated domains. Prospective theoretical/mathematical concepts or future observational/experimental instruments may alter our currently established knowledge in unconceived ways or may show that our current knowledge has a bounded validity. Thus, perspectivism invites us to exercise epistemological modesty, implying that scientific knowledge is not unconditionally true, but according to the scope and validity of our current theories and instruments.

But is M2 not a trivial view? That is, why would someone deny that what we take to be true is true according to currently accepted theories and instruments? The main issue is whether or not we can unconditionally state that current theories and instruments provide us with the ultimate picture of reality. Perspectivists make an effort to show that we cannot. (Realist) perspectivism is not entirely obvious. A number of scientists and philosophers presuppose that reality is exactly or approximately what science already describes. For instance, Giere ${ }^{49}$ discusses several objectivist expressions made by Steven Weinberg, a leading physicist. For another example, among philosophers, Gerald D. Doppelt ${ }^{50}$ seems to maintain that current best theories are ultimate and will not be replaced by better alternatives. ${ }^{51}$

One should note that M2 does not imply that experimental results are unreliable. According to the criterion of robustness, our belief in the truth of experimental results may well be justified. The perspectivist's point is that realist claims should be expressed in a conditional form. Accordingly, constancy of speed is a real property of light conditional on the experimental setups which have so far been performed in the contexts of inertial reference frames. Nor does M2 imply that experimental results are subjective. Perspectivism is at odds with objectivism in the sense of being capable of being viewed from nowhere (objectivism $)_{1}$ ). However, perspectivism does not underplay the role of objectifying procedures that help observers/experimenters to purify scientific knowledge from subjective errors. Indeed, perspectivism is consistent with a kind of fallible objectivism, such as the

\footnotetext{
${ }^{49}$ Giere, Scientific Perspectivism, 4-6.

${ }^{50}$ Gerald D. Doppelt, "From Standard Scientific Realism and Structural Realism to Best Current Theory Realism," Journal for General Philosophy of Science 42, no. 2 (2011): 295-316; Gerald D. Doppelt, "Best Theory Scientific Realism," European Journal for Philosophy of Science 4 (2014): 271-91.

${ }^{51}$ For a cogent criticism of his view, see Mario Alai, "Resisting the Historical Objections to Realism: Is Doppelt's a Viable Solution?," Synthese 194, no. 9 (2017): 3267-90.
} 
view developed by Alan Chalmers ${ }^{52}$ which emphasizes the capability of observational/experimental methods to eliminate subjective errors (objectivism $_{2}$ ). Objectivism ${ }_{2}$ conflicts with relativist subjectivism but not with perspectivism.

Anjan Chakravartty ${ }^{53}$ argues that the conditional nature of detection can be accepted by realists who accept the "dispositional" view of natural properties, and therefore there is no need for perspectivism. If Chakravartty's aim is to be defending objectivism ${ }_{2}$, then his position is hardly controversial. However, if he also supports objectivism ${ }_{1}$, his view is questionable. Particularly in special relativity, due to M1, properties such as simultaneity can hardly be understood objectively ${ }_{1}$ (they are not, and cannot be, measured/ observed from nowhere).

A relevant question is whether a dispositional account of properties can explain the frame-dependent properties of special relativity? I think it can, but not in a way that is incompatible with perspectivism. Chakravartty describes dispositions thus: "Dispositions are often manifested differently depending on the ambient circumstances, and while such manifestations can vary, they may be manifestations of one and the same property nonetheless." ${ }^{54}$ Let us examine the length of a rod, understood as a property of the rod. The length is "disposed" to be manifested differently in different reference frames. However, this is just another way of expressing the perspectival account. Since one cannot disregard reference frames in specifying the length of the rod, one has to accept the role of reference frames as perspectives. Consider Chakravartty's definition of a non-perspectival fact: "a proposition that is true, independently of any particular perspective one may take with respect to it." ${ }^{55}$ As I argued earlier, one cannot make a statement (or proposition) about the rod's length independently of any reference frame. Therefore, there is no non-perspectival fact about the length of the rod.

One may claim that "having a length" (or, in the dispositional language, "the capacity to have some length") is a reference-independent property of the rod, as the rod always has some length in any reference frame. This claim is trivial, and for this very reason the dispositional account needs perspec-

\footnotetext{
${ }^{52}$ Alan Chalmers, Science and Its Fabrication (Minnesota: University of Minnesota Press, 1990), chap. 4 and 5.

${ }^{53}$ Anjan Chakravartty, "Perspectivism, Inconsistent Models, and Contrastive Explanation," Studies in History and Philosophy of Science Part A 41, no. 4 (2010): section 3.

${ }^{54}$ Chakravartty, "Perspectivism," 409.

${ }^{55}$ Ibid., 407.
} 
tivism to jointly express that the capacity to have a length is a dispositional or potential property of the rod and the rod's realized length depends on the choice of frame. Similarly, concerning simultaneity, it is trivially correct that event ${ }_{1}$ is disposed to happen at the same time, before, or after event ${ }_{2}$ (provided it is not causally connected to event ${ }_{1}$ ). However, to specify which option is actually true, the reference frame should play its role to determine the perspective from which the events are observed. As a result, the dispositional account of properties can explain frame-dependent properties only jointly with perspectivism.

The dispositional account of properties is not in conflict with M2 either. The main point of (realist) perspectivism about experimental results is that they should not be expressed in an unconditional, universal way. Prospective theories or future technological instruments may demonstrate that some of the presuppositions behind our currently accepted (dispositional) facts are only valid in certain domains. Several cases from the history of science show that experimental results once considered to be unconditionally true have later turned out to be valid only under certain conditions. In this regard, a dispositional view that is compatible with the perspectivist's concern about experimental results is Hans Radder's Aristotelian account of "potentialities." ${ }^{56}$ Concerning the results of replicable experiments that are obtained by means of different experimental processes, he argues that

on the basis of a study of scientific practice we can only claim that replicable realizations of experiments have a nonlocal, and not a universal, range. [...] the nonlocal replicability of experimental results is accounted for on the basis of the independently persisting potentialities that are inherent in the things themselves. ${ }^{57}$

Accordingly, independent potentialities or dispositions explain the results of replicable experiments. But our knowledge of the results of these potentialities or dispositions is not "universally valid." The results may still be bounded to "nonlocal" conditions. This view is similar to Giere's argument that overlapping perspectives do not present "non-perspectival" facts. Further, according to Radder, our knowledge of potentialities or dispositions is not local either, since the results of replicable experiments transcend

${ }^{56}$ Has Radder, In and About the World: Philosophical Studies of Science and Technology (Albany, NY: State University of New York Press, 1996), chap. 4.

${ }^{57}$ Ibid., 83-84. 
local circumstances. ${ }^{58}$ In the perspectivists' terms, replicable experiments provide overlapping perspectives and not simply a single perspective. All in all, experimental results are neither local nor universal. The fact that they are not universal implies that they do not provide an ultimate image of reality.

All in all, a perspectival reading of special relativity is well motivated, and should be interesting for philosophers discussing scientific realism. Perspectivists should take the case of special relativity more seriously. The primary focus of this paper has been on special relativity. An independent study of the general theory of relativity might analyze its relationship with perspectivism more precisely. However, let me finish the paper by adding some comments on general relativity, which may bring a new perspective into the debate on perspectivism.

\section{The Perspective of General Relativity ${ }^{59}$}

The special theory of relativity is restricted to inertial reference frames, whereas general relativity discusses all frames, including non-inertial ones. In a general context, the theory provides formulas for physical measurements from any arbitrary reference frame, that is, from any state of motion, position, and time (with any speed and acceleration, anywhere and anytime in the universe). Interestingly, general relativity is also a theory of gravity, since according to its "principle of equivalence" the effects produced by a non-inertial reference frame and those by gravity are indistinguishable.

In general relativity, the "principle of relativity" is generalized to all reference frames, and thereby the "principle of covariance" is obtained: the laws of physics are the same in all frames of reference. However, from the perspective of general relativity, the speed of light is only constant clocally, where spacetime is flat. Measurements carried out in curved spacetime (that is, in the presence of gravity) vary from one event to another. Indeed, the coordinate speed of light (that is, the speed of light measured in a reference frame, using its local coordinates) is not the universal constant $c$. Thus, the coordinate speeds of light measured in different reference frames are differ-

\footnotetext{
${ }^{58}$ Ibid., section 5.4 .

${ }^{59} \mathrm{I}$ am grateful to one of the reviewers, whose comments are incorporated in this section. Specifically, the reviewer explained that the speed of light is only constant $c$ locally (the coordinate speeds of light measured in different reference frames are different) and that there are invariants with the same values for any observer in general relativity. Overall, the reviewer's comments enabled me to understand how general relativity can bring into the perspectival debate a crucial new perspective.
} 
ent and can be much bigger than $c$. There is of course no contradiction, since general relativity provides the mathematical formula that transforms the coordinate speed of light from one frame of reference to another. Locally the propagation of light at any event defines a unique light cone, which defines the local causal structure of the world.

According to general relativity, the speed of light can be straightforwardly understood as perspectival. When measured in a non-inertial frame, the speed of light is conditional on the proper acceleration of the frame (which is defined as the frame's acceleration relative to an inertial observer). The broader perspective of general relativity enables us to clearly see the perspectival nature of the speed of light in terms of its dependence on non-inertial frames. Accordingly, we know that the validity of special relativity is bounded to conditions. In Einstein's terms, "the special theory of relativity cannot claim an unlimited domain of validity; its results hold only so long as we are able to disregard the influences of gravitational fields on the phenomena (e.g., of light)." 60

Laws of physics are still frame-independent in general relativity. Also, there are invariants such as the Ricci scalar (or the scalar curvature) that have the same value in all reference frames. These invariants, which are typically the specific combinations of relative quantities, are frame-independent. Note, though, that they are independent of all reference frames, rather than of all perspectives whatsoever. If perspectivism is right, laws and invariant quantities can hardly be considered as "non-perspectival." They either are robust (in this case, they are not objectively true but are "nonlocally" true according to "overlapping perspectives") or are conditional on the a priori assumptions of the general theory of relativity.

General relativity has demonstrated the perspectivism of light speeds in terms of its frame-dependency. Similarly, prospective theories may provide broader perspectives, revealing some perspectival aspects or bounded validity of general relativity. In Giere's words, "the specific contingencies that sustained the earlier perspective became evident only from the vantage point of the later perspective. Often it is only from a new perspective that one can see, relative to that new perspective, where the earlier perspective was lacking." ${ }^{\prime \prime 1}$

${ }^{60}$ Albert Einstein, Relativity: The Special and the General Theory (New York: Pi Press, 2005), 98, emphasis added.

${ }^{61}$ Giere, Scientific Perspectivism, 94. 


\section{Acknowledgements:}

This paper is derived from my research at the Philosophy of Science Department of Sharif University of Technology, Iran. I am grateful to Javad Akbari Takhtameshlou for his guidance and to Ebrahim Azadegan for his support.

I am extremely grateful to two anonymous reviewers of this journal for their constructive comments, to Hans Radder for several valuable comments on the penultimate version of this paper, to James Read for very helpful comments on the paper's first draft and discussions on the geometrical and dynamical approaches to relativity, to Javad Ebadi for several insightful discussions on special relativity theory, and to the audience of the 7th Philosophy Student Conference, held in December 2020 at Tarbiat Modares University, Iran. I am also grateful to the organizers of the January 2020 Conference on the Foundations of Cosmology and Quantum Gravity at NYU Abu Dhabi, in particular to Kevin Coffey and Joshua Norton. My presence at the conference was supported by the NYU Abu Dhabi Institute and the Templeton Foundation.

I dedicate this paper to Hans Radder for his preciseness, candidness, and several kinds of unqualified support I have received from him.

\section{Bibliography:}

Alai, Mario. "Resisting the Historical Objections to Realism: Is Doppelt's a Viable Solution?” Synthese 194, no. 9 (2017): 3267-90.

Berghofer, Philipp. "Scientific Perspectivism in the Phenomenological Tradition." European Journal for Philosophy of Science 10 (2020): article number 30. https://doi.org/10.1007/s13194-020-00294-w.

Brown, Harvey R. Physical Relativity: Spacetime Structure from a Dynamical Perspective. Oxford: Oxford University Press, 2005.

Brown, Harvey R., and Oliver Pooley. "Minkowski Space-Time: A Glorious NonEntity." In The Ontology of Spacetime, edited by Dennis Dieks, 67-89. Amsterdam: Elsevier, 2006. https://doi.org/10.1016/S1871-1774(06)01004-7.

Brown, Harvey R., and James Read. “The Dynamical Approach to Spacetime Theories." In The Routledge Companion to Philosophy of Physics, edited by Eleanor Knox and Alastair Wilson. London: Routledge, 2021. 
Chakravartty, Anjan. "Perspectivism, Inconsistent Models, and Contrastive Explanation." Studies in History and Philosophy of Science Part A 41, no. 4 (2010): 405-12. https://doi.org/10.1016/j.shpsa.2010.10.007.

Chalmers, Alan. Science and Its Fabrication. Minnesota: University of Minnesota Press, 1990.

Doppelt, Gerald D. "From Standard Scientific Realism and Structural Realism to Best Current Theory Realism.” Journal for General Philosophy of Science 42, no. 2 (2011): 295-316. https://doi.org/10.1007/s10838-011-9167-8.

Doppelt, Gerald D. “Best Theory Scientific Realism.” European Journal for Philosophy of Science 4 (2014): 271-91. https://doi.org/10.1007/s13194-014-0090-9.

Einstein, Albert. “On the Electrodynamics of Moving Bodies.” In Hendrik A. Lorentz, Albert Einstein, Hermann Minkowski, and Hermann Weyl: The Principle of Relativity. New York: Dover Publications, 1952.

Einstein, Albert. “Time, Space, and Gravitation.” The Times, (November 28, 1919). Reprinted as “Doc. 26." In The Collected Papers of Albert Einstein, edited by Michael Janssen, Robert Schulmann, József Illy, Christoph Lehner, and Diana Kormos Buchwald, vol. 7. Princeton, NJ: Princeton University Press, 2002.

Einstein, Albert. Relativity: The Special and the General Theory. Translated by Robert W. Lawson. With an introduction by Roger Penrose and a commentary by Robert Geroch and a historical essay by David C. Cassidy. New York: Pi Press, 2005.

Eronen, Markus I. "Robustness and Reality." Synthese 192, no. 12 (2015): 3961-77. https://doi.org/10.1007/s11229-015-0801-6.

Evans, Peter. W. "Perspectival Objectivity or: How I Learned to Stop Worrying and Love Observer-Dependent Reality." European Journal for Philosophy of Science 10 (2020): article number 19. https://doi.org/10.1007/s13194-020-00286-w.

Fine, Kit. “Tense and Reality.” In Kit Fine: Modality and Tense: Philosophical Papers, 261-320. Oxford: Oxford University Press, 2005.

https://doi.org/10.1093/0199278709.003.0009.

Friedman, Michael. Foundations of Space-Time Theories. Princeton, NJ: Princeton University Press, 1983.

Finkelstein, Jerome. “One-Way Speed of Light?” American Journal of Physics 78, no. 8 (2010): 877. https://doi.org/10.1119/1.3364872. 
van Fraassen, Bas C. Scientific Representation: Paradoxes of Perspective. Oxford: Clarendon Press, 2008.

https://doi.org/10.1093/acprof:oso/9780199278220.001.0001.

Giere, Ronald. Scientific Perspectivism. Chicago: University of Chicago Press, 2006. https://doi.org/10.7208/chicago/9780226292144.001.0001.

Giere, Ronald. "Kuhn as Perspectival Realist.” Topoi 32 (2013): 53-57. https://doi.org/10.1007/s11245-012-9142-y.

Giere, Ronald. "Feyerabend's Perspectivism.” Studies in History and Philosophy of Science 57 (2016): 137-41. https://doi.org/10.1016/j.shpsa.2015.11.008.

Grünbaum, Adolf. Philosophical Problems of Space and Time. Dordrecht: D. Reidel, 1973. https://doi.org/10.1007/978-94-010-2622-2.

Grünbaum, Adolf. "David Malament and the Conventionality of Simultaneity: A Reply.” Foundations of Physics 40 (2010): 1285-97. https://doi.org/10.1007/s10701-009-9328-3.

Greaves, Eduardo, Michel Rodríguezb, and J. Ruiz-Camacho. "A One-Way Speed of Light Experiment.” American Journal of Physics 77, no. 10 (2009): 894-96. https://doi.org/10.1119/1.3160665.

Hacking, Ian. Representing and Intervening: Introductory Topics in the Philosophy of Natural Science. Cambridge: Cambridge University Press, 1983. https://doi.org/10.1017/CBO9780511814563.

Ismael, Jenann. "How Do Causes Depend on Us? The Many Faces of Perspectivalism." Synthese 193, no. 1 (2016): 245-67. https://doi.org/10.1007/s11229-015-0757-6.

Janis, Allen. “Conventionality of Simultaneity.” In Stanford Encyclopedia of Philosophy. Stanford University, 1997-. Article revised and published July 21, 2018. https://plato.stanford.edu/archives/fall2018/entries/spacetime-convensimul/.

Janssen, Michel. "Drawing the Line Between Kinematics and Dynamics in Special Relativity." Studies in History and Philosophy of Modern Physics 40, no. 1 (2009): 26-52. https://doi.org/10.1016/j.shpsb.2008.06.004.

Kosso, Peter. Appearance and Reality: An Introduction to the Philosophy of Physics. Oxford: Oxford University Press, 1998. https://doi.org/10.1119/1.18974.

Lipman, Martin A. "On the Fragmentalist Interpretation of Special Relativity." Philosophical Studies 177 (2020): 21-37. https://doi.org/10.1007/s11098-018-1178-4. 
Malament, David. "Causal Theories of Time and the Conventionality of Simultaniety.” Noûs 11, no. 3 (1977): 293-300. https://doi.org/10.2307/2214766.

Massimi, Michela. “Scientific Perspectivism and Its Foes.” Philosophica 84, no. 1 (2012): 25-52.

Massimi, Michela. "Four Kinds of Perspectival Truth." Philosophy and Phenomenological Research 96, no. 2 (2018): 342-59.

https://doi.org/10.1111/phpr.12300.

Massimi, Michela. "Perspectivism." In The Routledge Handbook of Scientific Realism, edited by Juha Saatsi, 164-75. New York: Routledge, 2018. https://doi.org/10.4324/9780203712498-14.

Massimi, Michela. "Realism, Perspectivism, and Disagreement in Science." Synthese (2019). https://doi.org/10.1007/s11229-019-02500-6.

Massimi, Michela, and Casey D. McCoy, eds. Understanding Perspectivism: Scientific Challenges and Methodological Prospects. New York: Routledge, 2020. https://doi.org/10.4324/9781315145198.

Maudlin, Tim. "Relativity and Space-Time Geometry." In The Routledge Companion to Philosophy of Physics, edited by Eleanor Knox and Alastair Wilson. London: Routledge, 2021.

Radder, Hans. In and About the World: Philosophical Studies of Science and Technology. Albany, NY: State University of New York Press, 1996.

Reichenbach, Hans. The Philosophy of Space \& Time. New York: Dover Publications, 1958.

Reicher, Maria. "Nonexistent Objects." In Stanford Encyclopedia of Philosophy. Stanford University, 1997-. Article revised and published March 19, 2019. https:/plato.stanford.edu/archives/win2019/entries/nonexistent-objects/.

Ryckman, Thomas. The Reign of Relativity: Philosophy of Physics 1915-1925. Oxford: Oxford University Press, 2005. https://doi.org/10.1093/0195177177.001.0001.

Rynasiewicz, Robert. “Definition, Convention, and Simultaneity: Malament's Result and its Alleged Refutation by Sarkar and Stachel." Philosophy of Science 68, no. 3 (2001): 345-57. https://doi.org/10.1086/392920.

Rynasiewicz, Robert. "Simultaneity, Convention, and Gauge Freedom." Studies in History and Philosophy of Modern Physics 43, no. 2 (2012): 90-94. https://doi.org/10.1016/j.shpsb.2012.01.004. 
Sarkar, Sahotra, and John Stachel. "Did Malament Prove the Non-Conventionality of Simultaneity in the Special Theory of Relativity?" Philosophy of Science 66, no. 2 (1999): 208-20. https://doi.org/10.1086/392684.

Salmon, Wesley C. "The Philosophical Significance of the One-Way Speed of Light.” Noûs 11, no. 3 (1977): 253-92. https://doi.org/10.2307/2214765.

Slavov, Matias. "Eternalism and Perspectival Realism about the 'Now." Foundations of Physics 50 (2020): 1398-410. https://doi.org/10.1007/s10701-020-00385-x.

Teller, Paul. "Modeling, Truth, and Philosophy." Metaphilosophy 43, no. 3 (2012): 257-74. https://doi.org/10.1111/j.1467-9973.2012.01745.x.

Teller, Paul. "What Is Perspectivism, and Does It Count as Realism?" In Understanding Perspectivism: Scientific Challenges and Methodological Prospects, edited by Michela Massimi and Casey D. McCoy, 49-64. New York: Routledge, 2020. https://doi.org/10.4324/9781315145198-4.

Wimsatt, William C. Re-Engineering Philosophy for Limited Beings: Piecewise Approximations to Reality. Cambridge, MA: Harvard University Press, 2007. https://doi.org/10.2307/j.ctvlpncnrh. 